\title{
UMA CRÍTICA AO PEDIDO DE AUMENTO DO MAR TERRITORIAL BRASILEIRA
}

A CRITICAL TO THE REQUEST FOR INCREASE IN THE BRAZILIAN TERRITORIAL SEA

Allen dos Santos Pinto da SILVA ${ }^{1}$

ISSUE DOI: $10.21207 / 1983.4225 .490$

\section{RESUMO}

Aborda-se a soberania brasileira sobre o mar territorial e suas áreas de atuação. O pleito de aumento do mar territorial brasileiro pode ocasionar não um benefício econômico, mas, sim, um risco ao país.

Palavras-chave: Zonas costeiras e mares. Soberania. Desenvolvimento.

\section{ABSTRACT}

1 Aluno do Mestrado de Direito da Universidade Cândido Mendes. Assessor de Órgão Julgador do TJRJ. E-mail allen.silva@gmail.com 
Brazilian sovereignty over the territorial sea and its areas of action is addressed. Since the increase in the Brazilian territorial sea may cause not an economic benefit, but a risk to the country.

Keywords: Coastal areas and seas. Sovereignty. Development.

\section{INTRODUÇÃO}

O Brasil, no ano de 2004, solicitou à Comissão de Limites da Plataforma Continental das Nações Unidas (CLPC) o aumento do seu mar territorial, com a intenção de instituir a Amazônia Azul, localizada na Zona Econômica Exclusiva brasileira.

Enquanto tramita o pleito, não se verifica nenhum aumento na atuação das Forças Armadas para proteger esse futuro e incerto território nacional.

Em tempos de crise, o que se pretende nesse artigo é analisar se vale a pena ser responsável por uma área maior do que se pode tutelar.

\section{NOSSA FRONTEIRA ESTÁ PROTEGIDA?}

Em 2007, um grupo bastante invulgar de náufragos deu à costa no norte da França. Era constituído por patinhos de borracha e acabava de concluir uma viagem épica com 15 anos de duração, iniciada em janeiro de 1992, data em que um navio que viajava entre Hong Kong e os Estados Unidos perdeu parte da carga durante uma tempestade. Um dos contentores caídos ao mar continha 28.800 brinquedos, alguns dos quais tinham aparecido anos antes na costa australiana e na costa leste dos Estados Unidos. Outros atravessaram o Estreito de Bering e o Oceano Ártico, tendo chegado à Gronelândia, ao Reino Unido e à Nova Escócia.2

Quando li a reportagem, conclui que estando no Rio de Janeiro, não veria os patos de borracha, principalmente após a despoluição da baía de Guanabara para as Olimpíadas.

2 http://www.eea.europa.eu/pt/sinais-da-aea/sinais-2014/em-analise/o-lixo-nosnossos-mares 
No entanto, vi o pato em águas brasileiras. O que me fez reflertir que a despoluição da baía de Guanabara não aconteceu, ou se aconteceu, só ficou "limpa" até o fechamento das Olimpíadas, ou melhor, até a abertura da tubulação da CEDAE que despeja esgoto sem qualquer intervenção do Estado ou do Poder Judiciário. Mas isso não é o assunto.

Após esse rápido desvio de rota, minha mente inquieta e instigada pelos estudos desenvolvidos no Mestrado de Direito promovido pela Universidade Cândido Mendes, e mais precisamente, por uma recente lembrança do seminário apresentado sobre Estado, não pude evitar o pensamento: esse pato fere a soberania brasileira? Traz algum prejuízo econômico?

\section{QUANDO O PATO INVADIU O TERRITÓRIO BRASILEIRO}

Ao naufragar em janeiro de 1992 no meio do Oceâno Pacífico ${ }^{3}$, aproximadamente os 29.000 mil patos velejaram 80.000 quilômetros em alto mar, até chegarem à costa brasileira e ultrapassarem o limite imposto pela legislação nacional e internacional quanto à faixa de mar territorial.

É sabido que o Estado brasileiro exerce soberania em relação à faixa correspondente ao seu mar territorial, bem como em relação ao espaço aéreo sobre o mar territorial e ao leito e subsolo sob o mar territorial.

Em que pese a soberania estatal sobre o mar territorial, a Convenção das Nações Unidas sobre o Direito do $\mathrm{Mar}^{4}$ assegura o direito de passagem inocente ${ }^{5}$ pelo mar territorial aos navios de todos os Estados. Aqui podemos responder parte da pergunta: Sim, o pato feriu a soberania

${ }^{3}$ ADAM, David. El naufragio de los patitos de goma. El Mundo: Crónica. Disponível em <http://www.elmundo.es/cronica/2003/408/1060606790.html>. Acesso em: 19/12/2017.

${ }^{4}$ Concluída em Montego Bay, Jamaica, em 10 de dezembro de 1982, entrou em vigor internacional e para o Brasil em 16 de novembro de 1994, através do Decreto $\mathrm{n}^{\circ} 1.530$, de 22 de junho de 1995.

${ }^{5}$ A passagem inocente originou-se na Corte Internacional de Justiça, no ano de 1947 com o caso Inglaterra X Albânia, pois esta omitiu-se em comunicar a presença de minas marítimas em suas águas territoriais, causando a destruição de embarcações inglesas. 
nacional ${ }^{6}$, visto que ultrapassou o limite estabelecido como passagem inocente e adentrou no mar territorial brasileiro sem permissão das autoridades competentes.

Define a Convenção que passagem inocente tem com requisito essencial a natureza rápida e sem interrupções, salvo as decorrentes de incidentes normais da navegação e as que se derem por motivo de força maior ou dificuldade grave, assim como as feitas por motivo de auxílio a pessoas, navios ou aeronaves em perigo ou dificuldades graves.

Define a Convenção como sendo passagem inocente o fato de um navio navegar pelo mar territorial com a finalidade de:

a) atravessar o mar territorial sem penetrar nas águas interiores, nem fazer escalas, em um ancoradouro ou instalações portuárias fora das águas interiores; e

b) dirigir-se para as águas interiores ou sair delas, ou fazer escalas em um ancoradouro ou instalações portuárias.

Não será considerada passagem inocente, dentre outras, quando no trânsito do navio, pelo mar territorial, este desenvolver qualquer atividade que não esteja diretamente relacionada com a passagem (art. 19, "l").

$\mathrm{Na}$ passagem inocente pelo mar territorial, submarinos ou quaisquer outros veículos submergíveis deverão navegar pela superfície e hastear o pavilhão de seu Estado de origem, obedecendo ao Landmark ${ }^{7}$ estabelecido pelo Brasil.

No que tange ao mar territorial, que abrange doze milhas marítimas de largura, medidas a partir da linha de baixa-mar do litoral continental e insular, tal como indicada nas cartas náuticas de grande escala, reconhecidas oficialmente no Brasil, ${ }^{8}$ não existe a permissão de livre acesso como na passagem inocente.

\footnotetext{
${ }^{6}$ Art. $1^{\circ}$ A República Federativa do Brasil, formada pela união indissolúvel dos Estados e Municípios e do Distrito Federal, constitui-se em Estado Democrático de Direito e tem como fundamentos: I - a soberania;

${ }^{7}$ Em português, o marco, no sentido de marco delimitador de terreno.

${ }^{8}$ Art. $1^{\circ}$, da Lei $n^{\circ} 8.617$, de 4 de janeiro de 1993.
} 
Nesse trecho de mar, a Marinha do Brasil junto com Força Aérea Brasileira exercem a tarefa de comando e controle constantemente com exercícios ar-superfície realizados por caças A-1 (AMX) da Força Aérea e A-4 Skyhawk da Marinha do Brasil.

Evidente que o pato, com seu reduzido tamanho, passou despercebido pelos radares e navegou tranquilo no trânsito de navios que navegavam pelo trecho de passagem inocente e depois pelo mar territorial independente de autorização prévia do Estado. O que faz refletir se nossas fronteiras estão realmente seguras, visto que a tecnologia avançada permite a construção de bombas e demais artefatos de destruição em massa em objetos pequenos e de, aparentemente, pouca expressão.

\section{O PATO DEU UM MERGULHO PROFUNDO E VIU COMO SOMOS RICOS}

Antes de chegar à praia, o pato navegou por um trecho do mar territorial brasileiro que abrange a plataforma continental que:

(...) compreende o leito e o subsolo das áreas submarinas que se estendem além do seu mar territorial, em toda a extensão do prolongamento natural de seu território terrestre, até o bordo exterior da margem continental, ou até uma distância de duzentas milhas marítimas das linhas de base, a partir das quais se mede a largura do mar territorial, nos casos em que o bordo exterior da margem continental não atinja essa distância. ${ }^{9}$

Temos que lembrar que o pato invasor vem de Hong Kong (China), que segundo relatório da Organização para Cooperação e Desenvolvimento Ecônomico (OCDE), tem um investimento de 3,6\% do PIB em educação, ou seja, o pato é superdesenvolvido.

Por isso, que com um mergulho o pato conseguiu perceber que antes do domínio brasileiro, existe uma grande fonte de riqueza no fundo do mar além das 200 milhas naúticas que hoje pertencem ao Brasil.

${ }^{9}$ Art.11, da Lei no 8.617, de 4 de janeiro de 1993. 
Nesse trecho, caso fosse um invasor e o pato desse um profundo mergulho, teria acesso à tecnologia utilizada no pré-sal, visto que a Petrobrás adotando uma política de domínio público não realizou o registro do avanço tecnológico oriundo das pesquisas da exploração do petróleo no pré-sal. E mais uma vez feriria a soberania brasileira, visto que nosso país é soberano na exploração dos recursos naturais sobre a plataforma continental, nos termos do Decreto $\mathrm{n}^{\circ}$ 99.165, de 12 de março de 1990, que promulgou a Convenção das Naços Unidas sobre o Direito do Mar. Abaixo segue uma ilustração que demonstra a profundidade da plataforma continental:

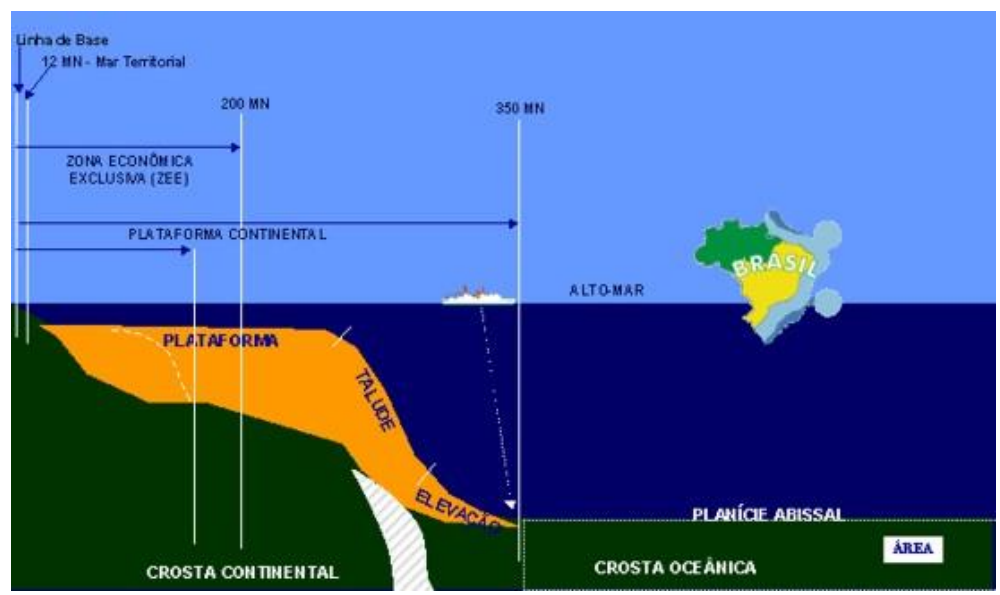

Fonte: Marinha do Brasil.

Se não fosse a ONU, o pato nesse mergulho teria infringido a soberania brasileira, visto que após ter passado o prazo de 10 anos instituído pela Convenção das Nações Unidas sobre o Direito do Mar (CNUDM), o Brasil no ano de 2004 solicitou à Comissão de Limites da Plataforma Continental das Nações Unidas (CLPC) o aumento do seu mar territorial, com a intenção de instituir a Amazônia Azul, localizada na Zona Econômica Exclusiva brasileira.

Esta Zona Econômica Exclusiva brasileira é uma área oceânica aproximada de 3,6 milhões de $\mathrm{km}^{2}$, os quais, somados aos cerca de 900 mil km² de extensão que o Brasil reivindica junto à Organização das 
Nações Unidas (ONU), irá perfazer um total aproximado de 4,5 milhões de $\mathrm{km}^{2}$.

Trata-se de uma extensa área oceânica, adjacente ao continente brasileiro, que corresponde a, aproximadamente, $52 \%$ da nossa área continental e que, devido à importância estratégica, às riquezas nela contidas e à imperiosa necessidade de garantir sua proteção, a Marinha do Brasil (MB), buscando alertar a sociedade sobre os seus incalculáveis bens naturais, sua biodiversidade e sua vulnerabilidade, passou a denominá-la "Amazônia Azul", cuja área é um pouco menor, porém em tudo comparável à “Amazônia Verde". ${ }^{10}$

Enquanto não é definido se o Brasil é soberano nesse território de $900 \mathrm{mil} \mathrm{km}^{2}$, o pato pode circular de forma inocente sem sofrer qualquer tipo de dano à sua navegação e curtindo toda paisagem paradisíaca e rica do nosso país.

\section{ANÁLISE ECONÔMICA DO DIREITO - O PEDIDO DE AUMENTO DO TERRITÓRIO NACIONAL}

De acordo com a breve pesquisa realizada, constata-se que ao solicitar o acréscimo territorial, os órgãos governamentais competentes não levaram em conta o custo para proteção da área objeto do requerimento feito para ONU. O que faz adentrar no ramo do Direito muitas vezes criticado pelos juristas, já que se aproxima da Economia: Análise Econômica do Direito.

A Análise Econômica do Direito pode ser situada no campo das disciplinas zetéticas, cujas investigações têm como objeto o direito no âmbito de outros campos do conhecimento; é uma disciplina concebida "como um corpo teórico fundado na aplicação da Economia às normas e instituições jurídico-políticas”. (SALAMA, 2008, p. 9)

$\mathrm{O}$ ambiente institucional em que vivemos, caracterizado por embates estéreis e incertezas, força-nos a desnudar as estratégias e os instrumentos jurídicos de que se pode lançar mão para a implementação de políticas públicas. Daí ser importante deixar bem vincado, desde logo, que a AED pode e deve ser aplicada em benefício da implementação de 
políticas públicas, com o escopo de incrementar o grau de eficácia material do ordenamento jurídico, em especial dos artigos 170, da Constituição do Brasil.

\begin{abstract}
A Análise Econômica do Direito tem por base os métodos da teoria microeconômica. Os agentes econômicos comparam os benefícios e os custos das diferentes alternativas antes de tomar uma decisão, seja ela de natureza estritamente econômica, seja ela de natureza social ou cultural. Estes custos e benefícios são avaliados segundo as preferências dos agentes e o conjunto de informação disponível no momento da avaliação. Esta análise de custobenefício é consequencialista porque leva em conta o que vai acontecer (em termos probabilísticos) depois de tomada a decisão, e não as causas que levaram à necessidade de tomar uma decisão. ${ }^{11}$
\end{abstract}

Pois bem, quando avaliamos o pleito de aumento do território brasileiro, que sendo aprovado gerará uma norma, estamos avaliando consequências que terão efeitos sobre toda sociedade. Afundada numa crise econômica, não soa bem pensar em aumento de custo no que tange à proteção da soberania nacional, através de um aumento do efetivo das Forças Armadas.

Nesse sentido, reforço que não é momento de se fazer projeções para situações hipotéticas, como foi o caso da exploração do pré-sal, que devido o alto custo para exploração ficou paralisado na pós-crise da Petrobrás.

O presente artigo não pretende aprofundar nessa Análise Econômica do Direito, mas, tão somente, fazer uma breve observação do quanto se faz necessário observar os efeitos de mais uma norma, consequência do eventual aceite pelo aumento do mar territorial, para o bem estar social do indivíduo.

\title{
CONSIDERAÇÕES FINAIS
}

${ }^{11}$ PORTO, José Maristrello. Análise Econômica do Direito (AED). 
Portanto, no momento que qualquer governo anuncia a descoberta e a exploração de importantes jazidas de petróleo, cresce também a cobiça internacional por estas áreas. Além disso, mais de $90 \%$ do comércio brasileiro são transportados através de seu mar territorial. Logo, proteger as rotas marítimas e as riquezas submersas é um fator que faz crescer a cada dia a importância da proteção à soberania brasileira. (Kaiser Konrad: 2011)

$\mathrm{E}$, por isso, nos termos da Lei $\mathrm{n}^{\circ} 8.617^{12}$, "o mar territorial brasileiro compreende uma faixa de doze milhas marítimas de largura" e "a soberania do Brasil estende-se ao mar territorial, ao espaço aéreo sobrejacente, bem como ao seu leito e subsolo", ao não ter o controle sobre a entrada ou saída de objetos não detectados pelos radares fiscalizadores, a soberania do país fica em risco e sua economia também.

Ainda em relação à pesquisa de petróleo, explica-se que em águas ultraprofundas (maiores que 2 mil metros) e sob camada rochosa de mais de $5 \mathrm{~km}$ de espessura, o pré-sal requer complexas tecnologias de ponta para o seu aproveitamento. ${ }^{13}$

E para chegar nessa tecnologia, o Brasil já gastou até hoje alguns bilhões de reais, no entanto, apresentou um índice de depósito de patentes inferior às demais empresas participantes dos consórcios formados para exploração do pré-sal. Segundo Gabriel Marcuzzo, que analisou o impacto do anúncio do governo brasileiro em 2007 relativo à descoberta das reservas do pré-sal sobre o depósito de patente de empresas do setor, o comportamento da Petrobrás pode estar vinculado a uma falta de política de propriedade industrial consistente por parte da empresa, especialmente quando se observa que o aumento de investimentos realizados pela empresas nos últimos des anos, inclusive com a expansão física de seu centro de pesquisas na UFRJ com o chamado CENPES 2, não tem sido acompanhado de um aumento na mesma proporção do número de depósitos de patentes ${ }^{14}$.

\footnotetext{
${ }^{12}$ Artigo $1^{\circ}$ e $2^{\circ}$, da Lei $n^{\circ} 8.617$, de 4 de janeiro de 1993.

${ }^{13}$ FIGUEIRÔA, Christiano Sávio Barros. Limites exteriores da plataforma continental do Brasil conforme o direito do mar. Brasília: FUNAG, 2014.

${ }^{14}$ CANTO, Cavalheiro Gabriel Marcuzzo; JOIA, Luiz Antonio; GONÇALVES, Ada Cristina. Strategic patenting in the upstream oil and gás industry: assessing the impacto $\mathrm{f}$ the pe-salt Discovery on patent applications in Brazil, World Patent Information, 2014, p.1-10.
} 
Além disso, a cláusula de investimentos em pesquisa, desenvolvimento e inovação (Cláusula de PD\&I) constante dos contratos para exploração, desenvolvimento e produção de petróleo e gás natural tem como objetivo estimular a pesquisa e a adoção de novas tecnologias para o setor, que é uma das atribuições da ANP, nos termos da Lei $n^{\circ}$ 9.478/1997.

No caso da exploração do petróleo na camada do pré-sal, o capital para o investimento de pesquisa foi emprestado pelo BNDES, que no seu Relatório "Perspectivas do Investimento 2010-2013", previu que o investimento previsto seria de $\mathrm{R} \$ 340$ bilhões de reais.

Ocorre que o desenvolvimento tecnológico teve como base um ICT, Instituição Tecnológica sem fins lucrativos, para realização de projetos de inovação em parceria com as empresas participantes dos consórcios, inclusive a Petrobrás, e nesse caso o BNDES não participa da titularidade da PI gerada ou dos resultados decorrentes dela.

O Brasil como um "player" de importância no cenário mundial deve garantir a soberania nacional sobre nossas riquezas (e sua importância política e econômica), de forma seja preservada a soberania e a integridade territorial, a realização dos seus interesses nacionais, livre de pressões e ameaças de qualquer natureza, e a garantia aos cidadãos do exercício dos direitos e deveres constitucionais.

Além da falta de controle, esse despreparo pode ocasionar perda econômica - em função da sonegação fiscal -, e problemas de saúde para a população, visto que a falta de controle sanitário na entrada de objetos não fiscalizados pode trazer vírus e ocasionar epidemias como as trazidas pelos europeus colonizadores para as Américas ${ }^{15}$.

Portanto, de nada adiantará o aumento solicitado pelo Brasil para aumento do mar territorial, se não tivermos uma proteção efetiva do mar territorial. Pois, bastará um simples pato de borracha, utilizando o exemplo do naufrágo supracitado, para entrar no território nacional e, sem ninguém perceber, causar um transtorno muito maior que um simples "quá, quá".

\section{REFERÊNCIAS BIBLIOGRÁFICAS}

15 http://www2.uol.com.br/historiaviva/reportagens/a_genetica_ajuda_a_esclare
cer_o_passado.html 
AGÊNCIA EUROPÉIA DO AMBIENTE. O lixo nos nossos mares. Article Publicado 2014-07-21. Modificado pela última vez 2016-04-22 11:32. Disponível em: <http://www.eea.europa.eu/pt/sinais-daaea/sinais-2014/em-analise/o-lixo-nos-nossos-mares>. Acesso em: 25 out. 2016.

BRASIL. "A Amazônia Azul”. Disponível em: <http://www.mar.mil.br/hotsites/sala_imprensa/html/amazul.html>. Acesso: 23 nov. 2016.

BRASIL. LEPLAC - AMAZÔNIA AZUL. Disponível em: <https://www.mar.mil.br/dhn/dhn/quadros/ass_leplac_amazul.html >. Acesso em: 23 nov. 2016.

CARVALHO, Gustavo de Lemos Campos. O mar territorial brasileiro de 200 milhas: estratégia e soberania, 1970-1982. Rev. bras. polít. int., Brasília , v. 42, n. 1, p. 110-126, jun. 1999. Disponível em <http://dx.doi.org/10.1590/S0034-73291999000100005>. Acesso em: 23 nov. 2016.

DE SOUZA, J. R. C. Estudo sobre mar territorial, zona contígua e zona econômica exclusiva. Consultor Legislativo da Área XVII Segurança e Defesa Nacional. Estudo Junho/2001. Disponível em: <http://www2.camara.leg.br/documentos-epesquisa/publicacoes/estnottec/arquivos-pdf/pdf/105053.pdf>. Acesso em : 23 nov. 2016.

DALLARI. Dalmo de Abreu. O Mar Territorial do Estado Brasileiro. Disponível em: <http://www.revistas.usp.br/rfdusp/article/viewFile/66716/69326.>. Acesso em: 12 nov. 2016.

FREITAS, Eduardo. Nova jazida de Petróleo do Brasil. Geografia humana do Brasil. Disponível em: <http://mundoeducacao.bol.uol.com.br/geografia/nova-jazidapetroleo-brasil.htm>. Acesso em: 12 nov. 2016.

FIGUEIRÔA, Christiano Sávio Barros. Limites exteriores da plataforma continental do Brasil conforme o direito do mar. - Brasília : FUNAG, 2014.

FIUZA. Bruno. Reportagem A genética ajuda a esclarecer o passado. O médico infectologista Stefan Cunha Ujvari conta como o estudo dos microrganismos pode contribuir para a pesquisa histórica. Disponível em http://www2.uol.com.br/historiaviva/reportagens/a_genetica_ajuda_a_ esclarecer_o_passado.html>. Acesso em: 23 nov. 2016. 
KONRAD, KAISER. Vigilância e controle aéreo do mar territorial brasileiro. Fonte: Diálogo. Posted. Disponível em: <https://dialogoamericas.com/pt/articles/vigilancia-e-controle-aereo-do-marterritorial-brasileiro>. Acesso em: 12 nov. 2016.

MATSUMOTO, Cássio Hatsumi. SILVA NETO. Messias Bezerra da. LIMA NETO, Rui Barbosa de. DAMASCENO, Helena Lucia. A soberania brasileira sobre o pré-sal: a utilização plena dos recursos oriundos da amazônia azul e sua logística. Disponível em: <https://www.marinha.mil.br/spolm/sites/www.marinha.mil.br.spolm/ files/126514.pdf2> . Acesso em: 23 nov. 2016.

PORTO, José Maristrello Porto;GRAÇA, Guilherme Mello. Análise Econômica do Direito (AED). FGV. Disponível em: <http://direitorio.fgv.br/sites/direitorio.fgv.br/files/u100/analise_econ omica_do_direito_20132.pdf>. Acesso em: 09 dez. 2016.

SANT'ANNA, André Albuquerque. Indústria de petróleo e gás: desempenho recente e desafios futuros . André Albuquerque Sant'Anna. Disponível em: <http://www.bndes.gov.br/SiteBNDES/export/sites/default/bndes_pt/ Galeri-

as/Arquivos/conhecimento/liv_perspectivas/02_Perspectivas_do_Inve stimento_2010_13_PETROLEO_E_GAS.pdf>. Acesso em: 12 nov. 2016.

SILVA, Alexandre Pereira da. O novo pleito brasileiro no mar: a plataforma continental estendida e o Projeto Amazônia Azul. Revista Brasileira de Política Internacional. On-line version ISSN 1983-3121. Rev. bras. polít. int. vol.56 no.1 Brasília 2013. Disponível em: <http://dx.doi.org/10.1590/S0034-73292013000100006>. Acesso: 23 nov. 2016.

SOUZA. J. M. Mar territorial, zona econômica exclusiva ou plataforma continental?. Revista Brasileira de Geofísica Print version ISSN 0102261X Rev. Bras. Geof. vol.17 n.1 São Paulo Mar. 1999. Disponível em: 〈http://dx.doi.org/10.1590/S0102-261X1999000100007〉. Acesso em:

25 . out. 2016. 